\title{
Instrumented nanoindentation investigation into the mechanical behavior of ceramics at moderately elevated temperatures
}

\author{
Vineet Bhakhri ${ }^{\text {a) }}$ \\ Centre for Advanced Structural Ceramics, Imperial College London, South Kensington Campus, \\ London SW7 2AZ, United Kingdom; and Department of Materials, Imperial College London, \\ South Kensington Campus, London SW7 2AZ, United Kingdom; and Department of Mechanical Engineering, \\ Imperial College London, South Kensington Campus, London SW7 2AZ, United Kingdom \\ Jianye Wang, Naeem Ur-rehman, and Constantin Ciurea \\ Centre for Advanced Structural Ceramics, Imperial College London, South Kensington Campus, \\ London SW7 2AZ, United Kingdom; and Department of Materials, Imperial College London, \\ South Kensington Campus, London SW7 2AZ, United Kingdom \\ Finn Giuliani \\ Centre for Advanced Structural Ceramics, Imperial College London, South Kensington Campus, \\ London SW7 2AZ, United Kingdom; and Department of Materials, Imperial College London, \\ South Kensington Campus, London SW7 2AZ, United Kingdom; and Department of Mechanical Engineering, \\ Imperial College London, South Kensington Campus, London SW7 2AZ, United Kingdom \\ Luc J. Vandeperre \\ Centre for Advanced Structural Ceramics, Imperial College London, South Kensington Campus, \\ London SW7 2AZ, United Kingdom; and Department of Materials, Imperial College London, \\ South Kensington Campus, London SW7 2AZ, United Kingdom
}

(Received 5 May 2011; accepted 19 July 2011)

\begin{abstract}
An analysis of indentation hardness data from three ceramic materials, zirconium diboride, silicon carbide, and titanium nitride, is presented to extract the fundamental deformation parameters at 295 to $623 \mathrm{~K}$. The measured activation volume was of the order of $1 \times b^{3}$ to $4 \times b^{3}$ (b is the Burgers vector). The calculated activation energies were in the range of 0.75 to $1.61 \mathrm{eV}$ and are typical of lattice-controlled dislocation glide mechanism. Using finite difference simulations, it was demonstrated that there is a significant difference between the plastic strain rate and the total strain rate for materials showing substantial elastic deformation (i.e., large hardness/elastic modulus ratio). Therefore, the measured total strain rates must be converted into plastic strain rates, which require a reduction during loading and an increase during the dwell at maximum load. Additionally, importance of quantification of instrumental thermal drift was discussed and use of either short duration indentation tests or high loads was emphasized.
\end{abstract}

\section{INTRODUCTION}

Ceramics in either bulk or thin film form have found considerable use where high temperatures and stresses are encountered, e.g., coatings for cutting tools or ceramic bearings. Furthermore, it has been observed that the hardness of these materials drops rapidly with temperature and more importantly that the room temperature hardness is not always a reliable indicator of the high temperature properties, see Fig. $1 .^{1-7}$ Given the considerable work done by Tabor, ${ }^{8-10}$ Marsh, ${ }^{11}$ Johnson, ${ }^{12}$ and many others, see e.g., Refs. 13-25, a clear link between the measured hardness and the uniaxial yield stress has now been established, provided other deformation mechanisms such as compaction, ${ }^{26-28}$ phase transformations, ${ }^{29-32}$

\footnotetext{
a) Address all correspondence to this author.

e-mail: v.bhakhri@imperial.ac.uk

DOI: $10.1557 /$ jmr.2011.246
}

and cracking ${ }^{33}$ are suppressed. Thus, it is reasonable to assume that the rapid change in hardness with temperature must be related to a rapid decrease in the resistance to dislocation flow.

The Peierls stress or lattice resistance for hard materials, such as ceramics, is very high, and hence it is reasonable to assume that the plastic deformation mechanism responsible for the high hardness, and its rapid decay, is glidecontrolled by the lattice resistance. In this mechanism, the movement of a dislocation by a single step through the lattice is the rate controlling step, and a simple model for the relation between the strain rate, $\frac{d \gamma}{d t}$, and shear flow stress, $\tau$, can easily be developed starting from the wellestablished relation between the strain rate, the mobile dislocation density, $\rho_{\mathrm{m}}$, and dislocation velocity, $\mathrm{v}$ :

$$
\frac{d \gamma}{d t}=\rho_{m} \cdot b \cdot \mathrm{v}
$$




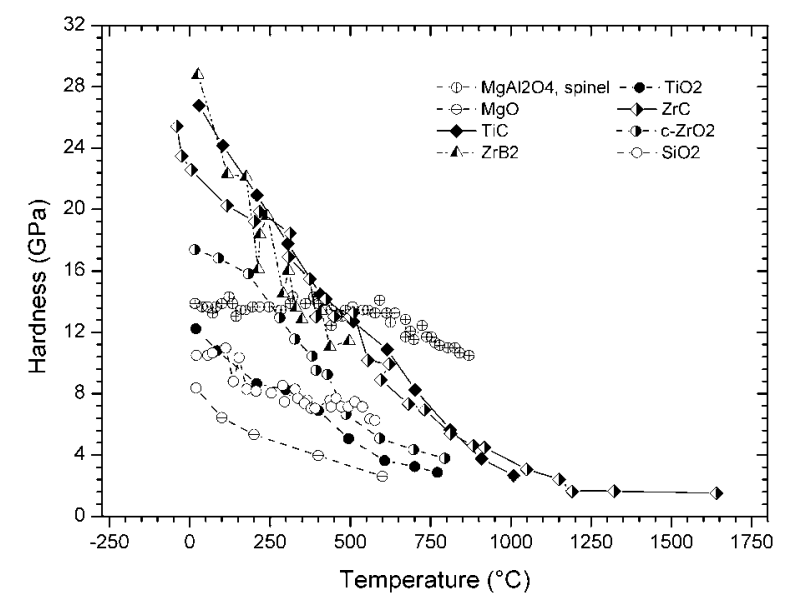

FIG. 1. Variation of hardness with temperature for a range of ceramic materials. The data was taken from the following sources: Spinel, ${ }^{1}$ $\mathrm{MgO},{ }^{2} \mathrm{TiC},{ }^{3} \mathrm{ZrB}_{2},{ }^{4} \mathrm{TiO}_{2},{ }^{5} \mathrm{ZrC}^{6}{ }^{6} \mathrm{c}-\mathrm{ZrO}_{2},{ }^{7}$ and $\mathrm{SiO}_{2} .{ }^{1}$

where the velocity of the dislocations can be estimated using a standard approach for a stress activated process:

$\mathrm{v}=\mathrm{v} \cdot b \cdot\left[\exp \left(-\frac{\left(\tau_{\mathrm{p}}-\tau\right) V}{k T}\right)-\exp \left(-\frac{\left(\tau_{\mathrm{p}}+\tau\right) V}{k T}\right)\right]$

where $v$ is the attempt frequency and $\tau_{\mathrm{p}}$ is the lattice resistance or the Peierls stress, which is the stress needed to make the dislocations move in the absence of any thermal energy. $\tau$ is the applied shear stress, $V$ is the activation volume, $T$ is the absolute temperature, and $k$ is the Boltzmann's constant. Combining these equations and solving for the applied shear stress yields the following relationship:

$$
\tau=\frac{k T}{V} \sinh ^{-1}\left[\frac{\frac{d \gamma}{d t}}{2 \cdot \rho_{\mathrm{m}} \cdot \nu \cdot b^{2}} \exp \left(\frac{\tau_{\mathrm{p}} V}{k T}\right)\right] .
$$

As long as $\tau \cdot V$ remains large relative to $k \cdot T$, the second term in the square brackets of Eq. (2) is much less than the first, and assuming further that the activation volume can be treated as constant, the expression can be simplified to:

$$
\tau=\tau_{\mathrm{p}}+\frac{k T}{V} \ln \left[\frac{d \gamma}{d t}\right]-\frac{k T}{V} \ln \left[\rho_{\mathrm{m}} \cdot b^{2} \cdot \mathrm{v}\right]
$$

This relationship forms the basis of typical analyses of compression tests at very elevated temperatures, see e.g., Refs. 34 and 35: a plot of the shear flow stress against the natural logarithm of strain rate, at a particular temperature, should result in a linear relationship with slope $k \cdot T / V$. Therefore, $V$ can be determined through the obtained slope. Similarly, a plot of shear flow stress versus temperature at fixed strain rate should yield a straight line with intercept equal to the Peierls stress and a slope proportional to

$$
\frac{k}{V} \ln \left(\frac{\frac{d \gamma}{d t}}{\rho_{\mathrm{m}} \cdot b^{2} \cdot v}\right),
$$

and can therefore be used to determine the mobile dislocation density using the activation volume determined earlier.

At more moderate temperatures, compression testing is generally replaced by hardness testing because if the load range is small enough, cracking can be suppressed, while in compression tests cracking can be difficult to suppress even with confining pressure. This has two additional advantages, firstly it can be used to measure the properties of thin films, which would otherwise be impossible and also for bulk materials the properties of individual grains can be measured. This allows fundamental properties of deformation of real materials to be measured without the complicating effects of defects such as grain boundaries. The recent advancements in the development of instrumented indentation has driven scientific community's interest to characterize these materials at microand nanoscales at ambient temperature. ${ }^{36}$ However, its use at higher temperatures is limited by several practical challenges such as increased rates of electronic and thermal drift arising from the extreme thermal sensitivity of the sensing and actuating devices in an instrumented indentation tester. ${ }^{37,38}$ In this work, we present the hardness results from indentation studies performed on various ceramic materials at ambient and moderately elevated temperatures. To make good use of the data provided by an instrumented indenter, an analysis of indentation hardness data is presented to extract fundamental deformation parameters, such as activation energy of the rate controlling process, activation volume, and the Peierls stress. We also discuss the experimental setup, the sources of errors and uncertainty in measured data, and the advantages and disadvantages of indenting single crystals versus polycrystalline ceramic materials. Finally, the limitations and advantages of indentations studies versus the very recently introduced microcompression tests ${ }^{39}$ are summarized.

\section{EXPERIMENTAL METHODS}

\section{A. Materials}

The materials investigated in this article were silicon carbide $(\mathrm{SiC})$, zirconium diboride $\left(\mathrm{ZrB}_{2}\right)$, and titanium nitride (TiN). These materials were selected as they are potential candidates for a range of high temperature applications: TiN is used in cutting tools, $\mathrm{SiC}$ is of interest as a fuel cladding for GEN IV nuclear reactors, and $\mathrm{ZrB}_{2}$ is one of the candidate materials for leading edges for future space re-entry vehicles. ${ }^{40,41}$ The $\mathrm{SiC}$ was produced by hot 
pressing $\mathrm{SiC}$ powder with addition of aluminium nitride (2-3.75 wt\%) and $3 \mathrm{wt} \%$ carbon, whereas the $\mathrm{ZrB}_{2}$ was obtained by pressureless sintering $\mathrm{ZrB}_{2}$ powder aided by addition of $1-3 \mathrm{wt} \%$ carbon. More details on the materials and their fabrication can be found in Refs. 42-44. To contrast these measurements on polycrystalline materials with results obtained on single crystals, indentation was also carried out into the basal plane of $\mathrm{SiC}$ single crystals of the $6 \mathrm{H}$ and $4 \mathrm{H}$ polytypes (Pi-Kem Ltd., Staffordshire, United Kingdom) and in the (001) plane of a single crystal TiN.

\section{B. Indentation experiments}

Indentation experiments were carried out at five temperatures between 295 and $623 \mathrm{~K}$ using a Nanotest Platform 2 (Micromaterials Ltd., Wrexham, United Kingdom). For these experiments, a dual heater arrangement was used, where a miniature heater was attached to the diamond Berkovich tip and a separate heater was used to heat the specimen. This type of arrangement ensures that the indenter and the test sample are at the same temperature and reduces the amount of thermal drift in the measured indentation depth signal. Thermal drift measurements were made pre- and postindentation cycles by monitoring the change in depth signal at miniscule constant load condition over 60 s. For both $\mathrm{SiC}$ and $\mathrm{ZrB}_{2}$, the indentation schedule, at $295,373,473$, and $573 \mathrm{~K}$, consisted of the following sequence: the thermal stability of the capacitive displacement sensor was measured for $60 \mathrm{~s}$ before the experiment, followed by a $60 \mathrm{~s}$ thermalization period. Then the indentation load was increased at a fixed rate to a predetermined maximum value of 50,100 , and $200 \mathrm{mN}$. The maximum load was maintained for $60 \mathrm{~s}$ before unloading at the same rate as during loading. A second stability measurement was carried out during unloading at $10 \%$ of the maximum load. The measured drift of the sensor was typically $0.02 \mathrm{~nm} \mathrm{~s}^{-1}$ at room temperature experiment, $0.1 \mathrm{~nm} \mathrm{~s}^{-1}$ for $373 \mathrm{~K}$, and $0.2 \mathrm{~nm} \mathrm{~s}^{-1}$ at $573 \mathrm{~K}$. For each temperature, three different loading rates were used so that the maximum load was reached respectively in 4,20 , or $100 \mathrm{~s}$. This enabled us to capture the indentation hardness data at three different strain rates measured at the end of loading section for these materials. An advantage of performing an indentation experiment consisting of a loading stage and a constant-load dwell stage is that this type of test captures a wide range of strain rates, ranging from $0.1 \mathrm{~s}^{-1}$ to $10^{-2} \mathrm{~s}^{-1}$ for loading stage and $10^{-3}$ to $10^{-5} \mathrm{~s}^{-1}$ during constant-load dwell stage. A similar test schedule for TiN was used, where indenter was loaded at a constant rate to reach the maximum load of $60 \mathrm{mN}$ in $20 \mathrm{~s}$ followed by a $5 \mathrm{~s}$ dwell at 295, 373, 473, 573, and $623 \mathrm{~K}$. Then indenter was unloaded at original loading rate. Thermal drift measurements were made both before and after the indentation cycles. The measured average thermal drift for this material was $0.02 \mathrm{~nm} \mathrm{~s}^{-1}$ at room temperature and $0.1 \mathrm{~nm} \mathrm{~s}^{-1}$ at
$623 \mathrm{~K}$. It must be stressed that it is crucial that the indenter and sample have both reached stable temperatures when the experiments are started as otherwise thermal drift can be much higher and high enough to render any data collected unusable.

\section{DATA ANALYSIS}

\section{A. Extracting hardness values from loading and dwell data}

For ceramics materials, the method developed by Oliver and Pharr ${ }^{45}$ remains the most commonly used to extract the Young modulus and hardness from the loaddisplacement data. The method recognizes that during indentation the total displacement, $h_{\mathrm{t}}$, is the combination of an elastic deflection by the surface, $h_{\mathrm{e}}$, and a distance over which indenter and material are in contact, $h_{\mathrm{c}}$. Hence to extract the area over which there is contact between the indenter and the sample, a value for $h_{\mathrm{c}}$ must be determined. Oliver and Pharr showed using Sneddon's ${ }^{46}$ work that the contact height can be calculated using:

$$
h_{\mathrm{c}}=h_{\mathrm{t}}-\varepsilon \frac{F}{S},
$$

where $F$ is indentation load, $S$ is the slope of the unloading curve at the onset of unloading, and $\varepsilon$ is a constant, which typically is taken as 0.75 . A separate calibration method allows relating the area of indenter, $A_{\mathrm{c}}$, with the contact height:

$$
A_{\mathrm{c}}=f\left(h_{\mathrm{c}}\right)
$$

So that once the contact height is known, the hardness is easily calculated from

$$
H=\frac{F}{A_{\mathrm{c}}}
$$

Moreover, Oliver and Pharr also showed that the slope of the unloading curve is directly related to the area of contact and the stiffness of the material, so that the experiment also yields an estimate for the reduced modulus of the contact through:

$$
E_{\mathrm{r}}=\frac{S}{2} \sqrt{\frac{\pi}{A_{\mathrm{c}}}},
$$

where the reduced modulus is a combination of the Young modulus, $E$, and Poisson ratio, $v$, of the indenter and the sample, respectively:

$$
\frac{1}{E_{\mathrm{r}}}=\frac{1-v_{\mathrm{s}}^{2}}{E_{\mathrm{s}}}+\frac{1-v_{\mathrm{i}}^{2}}{E_{\mathrm{i}}}
$$


The limitations of this method are that only one hardness value is extracted per experiment because an unloading slope is needed and that the measured hardness does not reflect the strain rate during loading because even a short dwell to equilibrate the displacement is sufficient for loading effects to be eradicated by further flow. ${ }^{47,48}$

The need to know the elastic modulus to derive a hardness from loading data has lead to developments where the unloading slope is measured during loading using a small perturbation to the force signal, see e.g., Ref 49 for a review. However, two recent studies ${ }^{50,51}$ have raised questions on the credibility of data obtained by the continuous stiffness measurement technique and underscore vital practical limitations particularly for soft materials such as polymers. For the bulk materials under investigation here, it can be assumed that the stiffness of the material is not a function of indentation depth and therefore a virtual unloading slope can be calculated from the stiffness as determined from the final unloading slope:

$$
S=2 E_{\mathrm{r}} \sqrt{\frac{A_{\mathrm{c}}}{\pi}}
$$

Substitution of this slope in Eq. (5) yields the following identity:

$$
h_{\mathrm{c}}=h_{\mathrm{t}}-\varepsilon \frac{F}{2 E_{\mathrm{r}}} \sqrt{\frac{\pi}{A_{\mathrm{c}}}}
$$

The contact height, $h_{\mathrm{c}}$, is the only unknown in this equation, but it appears on both sides as the contact area is also a function of the contact height. The correct value can be found easily by iteration yielding a hardness values for every $\left(h_{\mathrm{t}}, F\right)$ data pair. The same approach can be used to analyze the indentation data collected during a hold period at maximum load.

\section{B. Assigning a strain rate to indentation data}

The definition of an effective strain rate for indentation experiments is well established although a range of measures are used. ${ }^{52}$ In this work, the choice was made to use the following definition:

$$
\varepsilon^{\prime}=\frac{d \varepsilon}{d t}=\frac{1}{h_{\mathrm{t}}} \cdot \frac{d h_{\mathrm{t}}}{d t}
$$

where $h_{\mathrm{t}}$ is the total displacement of the indenter. The advantage of this parameter is that it can be used conveniently as a consistent measure for the strain rate during both the loading segment and the constant load segment. To stabilize the numerical evaluation of the differential of the displacement, curves were fitted to the data, and the differential was calculated by differentiating the fitted curves. A power law relationship between time and displacement and a logarithmic relationship between time and displacement was used for the loading and hold segments, respectively. For each loading segment and each dwell at maximum load, the average hardness and strain rate were calculated. During loading, only the top half of the data was included to reduce the influence of errors at small contact depths and potential influences of indentation size. During the dwell, for $\mathrm{SiC}$ and $\mathrm{ZrB}_{2}$, the data of the first $10 \mathrm{~s}$ was discarded to allow the transient between the two loading modes to subside.

While expressions for the strain rate are well established, the strain rate used in the definition of the plastic constitutive law above is the strain rate carried by the dislocations, i.e., it is a plastic strain rate rather than the overall strain rate. When strain hardening is limited, this distinction is not important in uniaxial tests when there is little or no further elastic loading once yielding commences, i.e., the plastic and the total strain rate are equal. During indentation of materials with high hardness/elastic $(H / E)$ modulus ratio, the elastic displacements continue to accumulate and there might, therefore, be a substantial difference between the total and plastic strain rates. Therefore a number of finite difference simulations were carried out to investigate the relationship between the plastic strain rate and the total strain rate for materials showing substantial elastic deformation (large $H / E$ ). The total strain rate should be the sum of the plastic and elastic strain rates:

$$
\varepsilon_{\mathrm{tot}}^{\prime}=\frac{1}{h_{\mathrm{t}}} \frac{d h_{\mathrm{t}}}{d t}=\varepsilon_{\mathrm{p}}^{\prime}+\varepsilon_{\mathrm{el}}^{\prime}
$$

which with reference to Fig. 2 can be ensured by defining the plastic strain rate as

$$
\varepsilon_{\mathrm{p}}^{\prime}=\frac{1}{h_{\mathrm{t}}} \frac{d h_{\mathrm{p}}}{d t}
$$

and the elastic strain rate as

$$
\varepsilon_{\mathrm{el}}^{\prime}=\frac{1}{h_{\mathrm{t}}} \frac{d h_{\mathrm{t}, \mathrm{el}}}{d t}
$$

The nomenclature used in Fig. 2 for the different distances differs only slightly from the choices made in the work by Oliver and Pharr, ${ }^{45}$ but offers the advantage that the definition of a plastic height $h_{\mathrm{p}}$ rather than a contact

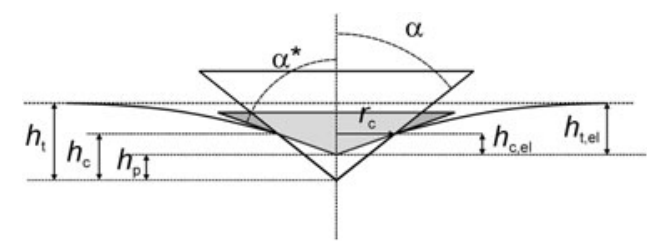

FIG. 2. Geometrical relations for indentation by a cone with included semiangle $\alpha$, and for purely elastic indentation by a cone with included semiangle $\alpha^{*}$, which represents the elastic component of the deformation. 
height allows for a smooth transition into the limiting case for materials where no elastic deflections occur $(H / E \sim 0$, $\alpha^{*}=\pi / 2$ ) and the limiting case where no plastic flow occurs. For the latter, $\tan \alpha^{*}=\tan \alpha$ and the pressure is given by Sneddon's solution:

$$
P_{\mathrm{el}}=\frac{E_{\mathrm{r}}}{2 \tan \alpha^{*}}
$$

To simulate the experiments, it is assumed that when the experiment starts $h_{\mathrm{p}}=0$. It then suffices to derive the evolution of $h_{\mathrm{p}}$ with time from the constitutive equation of the material and to determine all elastic parameters as a function of applied force and $h_{\mathrm{p}}$. For the constitutive relationship, it is assumed here that the hardness and plastic strain rate are related through:

$$
H=H_{0}+H_{\mathrm{s}} \ln \varepsilon_{\mathrm{p}}^{\prime},
$$

which was chosen as it is of the same form as the constitutive equation, Eq. (4), for dislocation flow used in this work. Here, $H_{\mathrm{s}}$ is the strain rate sensitivity of the hardness. Note that other relationships, such as a power law, could be used instead. The evolution of the change in plastic height, $h_{\mathrm{p}}$, with time can then be obtained from:

$$
\frac{d h_{\mathrm{p}}}{d t}=h_{\mathrm{t}} \cdot \exp \left(\frac{H-H_{0}}{H_{\mathrm{s}}}\right)
$$

To derive the elastic parameters, use is made of a number of relationships that can be derived from Fig. 2 yielding an expression for the contact area in terms of the plastic height and the elastic contact height as:

$$
A_{\mathrm{c}}=\pi r_{\mathrm{c}}^{2}=\pi\left(h_{\mathrm{c}} \tan \alpha\right)^{2}=\pi\left(\left[h_{\mathrm{c}, \mathrm{el}}+h_{\mathrm{p}}\right] \tan \alpha\right)^{2} .
$$

Hence, the hardness is found as:

$$
H=\frac{F}{\pi\left(\left[h_{\mathrm{c}, \mathrm{el}}+h_{\mathrm{p}}\right] \tan \alpha\right)^{2}} .
$$

Both the imaginary cone causing the elastic deformation and the actual cone must experience the same pressure ${ }^{14}$ therefore hardness must be equal to the elastic equilibrium pressure on the imaginary cone, hence:

$$
\frac{F}{\pi\left(\left(h_{\mathrm{c}, \mathrm{el}}+h_{\mathrm{p}}\right) \tan \alpha\right)^{2}}=\frac{E_{\mathrm{r}}}{2 \tan \alpha^{*}},
$$

where $\tan \alpha^{*}=\left(1+\frac{h_{\mathrm{p}}}{h_{\mathrm{c}, \mathrm{l}}}\right) \tan \alpha$ so that

$$
h_{\mathrm{c}, \mathrm{el}}^{2}+h_{\mathrm{c}, \mathrm{el}} h_{\mathrm{p}}-\frac{2}{\pi} \frac{F}{\tan \alpha \cdot E_{\mathrm{r}}}=0 .
$$

This is a quadratic equation with solution

$$
h_{\mathrm{c}, \mathrm{el}}=\frac{-h_{\mathrm{p}}+\sqrt{h_{\mathrm{p}}^{2}+\frac{8}{\pi} \frac{F}{\tan \alpha \cdot E_{\mathrm{r}}}}}{2} .
$$

Using Sneddon's ${ }^{46}$ relationship between the different heights for an elastic contact:

$$
h_{\mathrm{c}, \mathrm{el}}=\frac{2}{\pi} h_{\mathrm{t}, \mathrm{el}} \quad,
$$

the total elastic displacement, $h_{\mathrm{t}, \mathrm{el}}$, is therefore given as:

$$
h_{\mathrm{t}, \mathrm{el}}=\frac{\pi}{2} h_{\mathrm{c}, \mathrm{el}}=\frac{\pi\left(-h_{\mathrm{p}}+\sqrt{h_{\mathrm{p}}^{2}+\frac{8}{\pi} \frac{F}{\tan \alpha \cdot E_{\mathrm{r}}}}\right)}{4} .
$$

With these expressions, all elastic and total displacements can be calculated for any given force at any given time. The rate of change of $h_{\mathrm{p}}$ with time can then be calculated using Eq. (18) and hence the value for $h_{\mathrm{p}}$ in the next time step can be found and therefore the entire experiment can be simulated. A series of simulations is carried out using following materials parameters; $H=10-38 \mathrm{GPa}, E=100-1000 \mathrm{GPa}$, Poisson's ratio, $v=0.15$. For the strain rate sensitivity, $H_{\mathrm{s}}$, values between $1 \%$ and $10 \%$ of $\mathrm{H}$ were considered. Experiments were simulated for a loading time of 2 to $1000 \mathrm{~s}$ and dwell time at the maximum load was taken to be $60 \mathrm{~s}$. The results from these simulations are discussed in Section IV.

\section{Hardness to shear flow stress conversion}

The hardness values obtained were converted into shear flow stress values using the analytical relationship between hardness, $H$, and yield stress, $Y$, derived by Vandeperre et al. ${ }^{14}$ by modifying the expanding cavity solution of Hill ${ }^{53}$ :

$$
\begin{aligned}
\frac{H}{Y}=\frac{2}{3}\{ & 1+\frac{3}{3-6 \lambda} \ln \\
& \left.\times\left(\frac{(3+2 \mu) \cdot(2 \lambda \cdot(1-\zeta)-1)}{(2 \lambda \mu-3 \mu-6 \lambda) \cdot \zeta}\right)\right\},
\end{aligned}
$$

with:

$\zeta=\frac{E_{\mathrm{r}}}{E_{\mathrm{r}}-2 H \tan \alpha}, \quad \lambda=\frac{(1-2 v) Y}{E}, \quad \mu=\frac{(1+v) Y}{E}$,

where $E$ is the Young modulus, $E_{\mathrm{r}}$ is reduced modulus, $v$ is Poisson ratio, and $\alpha$ the included equivalent semi-angle of the indenter. Uniaxial yield stress values were converted into shear flow stress by dividing by 2 , consistent with the Tresca yield criterion used in deriving the expanding cavity solution. 


\section{RESULTS}

Figure 3 illustrates a typical result for the different displacements versus time obtained by finite difference simulation. During loading both the elastic and the plastic displacement increases [Fig. 3(a)], whereas during the hold at maximum load, the plastic displacement continues to increase but the total elastic displacement decreases [Fig. 3(b)]. Hence, the relationship between plastic strain rate and total strain rate is different during loading and holding at maximum load. The resulting trends from simulations in Fig. 4 show that the ratio of total strain rate to plastic strain rate increases with $H / E$ whereas it decreases with $H / E$ during dwelling at maximum load.

For proportional loading $\left(\frac{1}{F} \frac{d F}{d t}\right.$ constant), it can be shown that the ratio of strain rates is equivalent to the ratio of $h_{\mathrm{t}}$ to $h_{\mathrm{p}}$ and an analytical expression for this ratio is:

$$
\frac{\varepsilon_{\mathrm{t}}^{\prime}}{\varepsilon_{\mathrm{p}}^{\prime}}=\frac{h_{\mathrm{t}}}{h_{\mathrm{p}}}=\frac{\frac{E_{\mathrm{r}}}{H_{\mathrm{L}}}+(\pi-2) \tan \alpha}{\frac{E_{\mathrm{r}}}{H_{\mathrm{L}}}-2 \tan \alpha},
$$

where $H_{\mathrm{L}}$ is the measured hardness during loading. For constant rate loading, good agreement could be obtained for a wide range of parameters, if the average measured hardness during loading is decreased by a $\times H_{\mathrm{s}}$ and $a$ is a factor which depends on the extent of the data included in calculating the average strain rate and hardness. If the data included in the average is the data from $50 \%$ of the maximum load onwards, $a=1.53$. Hence, determining the plastic strain rate for constant loading rate data needs to be an iterative process as knowledge of $H_{\mathrm{s}}$ is needed. However, typically one iteration suffices. Hence, proportional loading is slightly more convenient but both methods can be used. For the unloading, the data converged when plotted against $H_{\mathrm{D}} / E_{\mathrm{r}}$, with $H_{\mathrm{D}}$ the average hardness during the dwell. The trend could be fitted by:

$$
\frac{\varepsilon_{\mathrm{t}}^{\prime}}{\varepsilon_{\mathrm{p}}^{\prime}}=\frac{1}{1+10.54148\left(\frac{H_{\mathrm{D}}}{E_{\mathrm{r}}}\right)+25.83252 \cdot\left(\frac{H_{\mathrm{D}}}{E_{\mathrm{r}}}\right)^{2}}
$$

Hence, to obtain the properties against the plastic strain rate, the strain rates calculated during loading need to be reduced whereas the strain rates calculated during the dwell at maximum load need to be increased. It is worth stressing that these findings will have almost no influence on the determination of the strain rate dependence of the hardness of many metals, as for low values of $H / E_{\mathrm{r}}$, the total strain rate is nearly equal to the plastic strain rate and there is little difference between the values obtained during loading or dwelling.

Now, we present the results from three different ceramic systems;
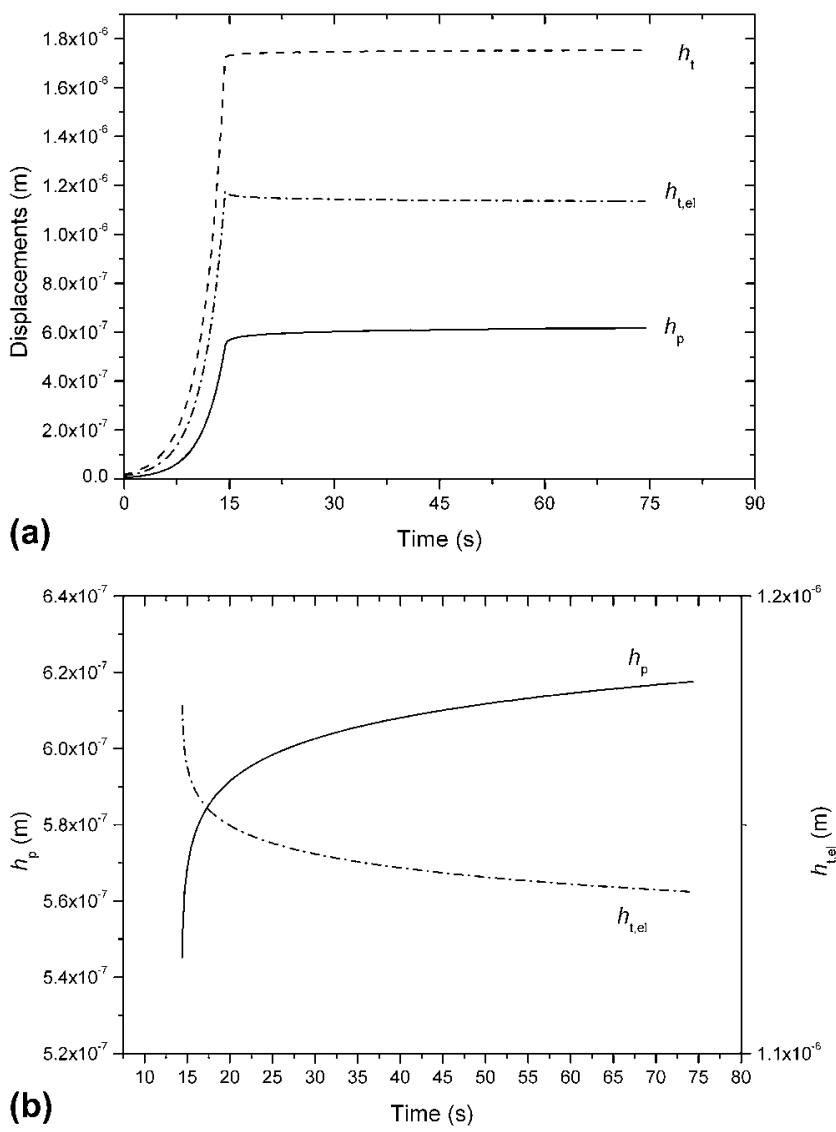

FIG. 3. (a) Displacement versus time for proportional loading $\left(0.625 \mathrm{~s}^{-1}\right)$ of a material with $H_{0}=10 \mathrm{GPa}, H_{\mathrm{s}}=0.1 \mathrm{GPa}$, $E=100 \mathrm{GPa}$, and $v=0.15$. The maximum load was maintained for $60 \mathrm{~s}$ after the end of loading. (b) Detail of the variation of the elastic and plastic components of the displacement with time during the dwell at maximum load.

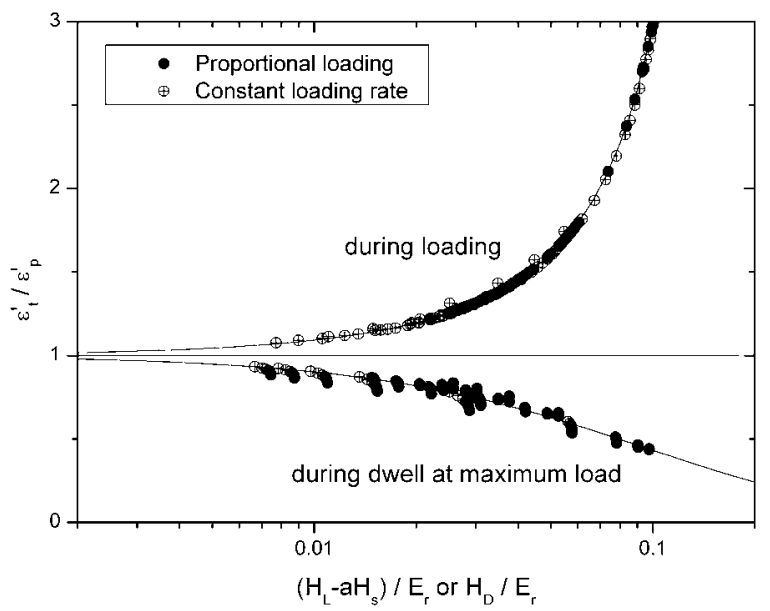

FIG. 4. Ratio of the total to the plastic strain rate during either loading or during dwelling at maximum load as a function of the hardness (average loading hardness $H_{\mathrm{L}}$, average dwell hardness, and $H_{\mathrm{D}}$, strain rate sensitivity $\left.H_{\mathrm{s}}\right)$ to reduced modulus, $E_{\mathrm{r}}(a=0$ for proportional loading and $a=1.52$ for constant loading rate when only data above $50 \%$ of the maximum load is included). 


\section{A. $\mathrm{ZrB}_{2}$}

Figure 5(a) shows the hardness versus plastic and total strain rates at different temperatures. The data points show the average for each of the strain-rate ranges (three on the right defined by the loading rate, one on the left defined by the self-equilibration during a dwell at maximum load). The plot demonstrates that the change in strain rate upon converting between total and plastic strain rates is limited. Moreover as illustrated in Table I, the strain rate sensitivity based on the loading data alone is not changed significantly whether it is calculated from total or plastic strain rate. The difference is typically less than $1 \%$ with a maximum difference observed of $6 \%$. However, the small changes are sufficient to cause a noticeable change in the strain rate sensitivity when data from both loading and dwell experiments are used together. Figure 5(a) also illustrates that the corrections needed diminish as temperature, $T$, increases. This is due to the fact that $H / E_{\mathrm{r}}$ decreases with increasing temperature (see Fig. 4).

Figure 5(b) shows the average shear stress versus plastic strain rate for four different temperatures as determined from the hardness data. To calculate constitutive data for lattice resistance dominated plastic flow from the experimental results for $\mathrm{ZrB}_{2}$, Eq. (4) is used. The variation of shear flow stress with strain rate, Fig. 5(b), results in a linear relationship with slope $k \cdot T / V$. The measured apparent activation volume is $3.93 \times 10^{-9} \mathrm{~m}^{3}$, i.e., $1.24 \times b^{3}$.

To compare this estimate with established values, activation volumes, $V$, were calculated from the activation energy, $Q$, and the Peierls stress, $\tau_{\mathrm{p}}$, values reported by Frost and Ashby ${ }^{55}$ using the assumption that the activation volume, the activation energy, and the Peierls stress can be related through $Q=\tau_{\mathrm{p}} \times V$. Our estimate for $\mathrm{ZrB}_{2}$ is of the same order as the values for $\mathrm{TiC}\left(0.96 \times b^{3}\right), \mathrm{ZrC}$ $\left(1.25 \times b^{3}\right)$, Si $\left(2.86 \times b^{3}\right)$, and Ge $\left(3.33 \times b^{3}\right)$, which were derived from microhardness measurements, confirming that our nanoindentation data gives results consistent with other indentation experiments. In addition, the activation volume as derived from compression tests on $\mathrm{MgO}$ samples oriented for slip on $<011>\{100\}$ was found to be $2.29 \times b^{3}$, which is also of the same order of magnitude. Hence, indentation and compression tests appear to give similar estimates.

In deriving our result for $\mathrm{ZrB}_{2}$, the Burgers vector, $b$, was assumed to be any of the a- vectors of the hexagonal crystal in line with reports on slip in $\mathrm{ZrB}_{2} \cdot{ }^{54,55}$ Variation of flow stress with temperature at constant strain rate, Eq. (4), provides the Peierls stress estimate to be $6.6 \pm 0.7 \mathrm{GPa}$, and assuming the attempt frequency to be of the order of $10^{11} \mathrm{~s}^{-1}$, following Frost and Ashby, ${ }^{56}$ the mobile dislocation density is estimated as a range from $2 \times 10^{14} \mathrm{~m}^{-2}$ to $1 \times 10^{18} \mathrm{~m}^{-2}$. The large uncertainty on this estimate indicates that it is difficult to give any real
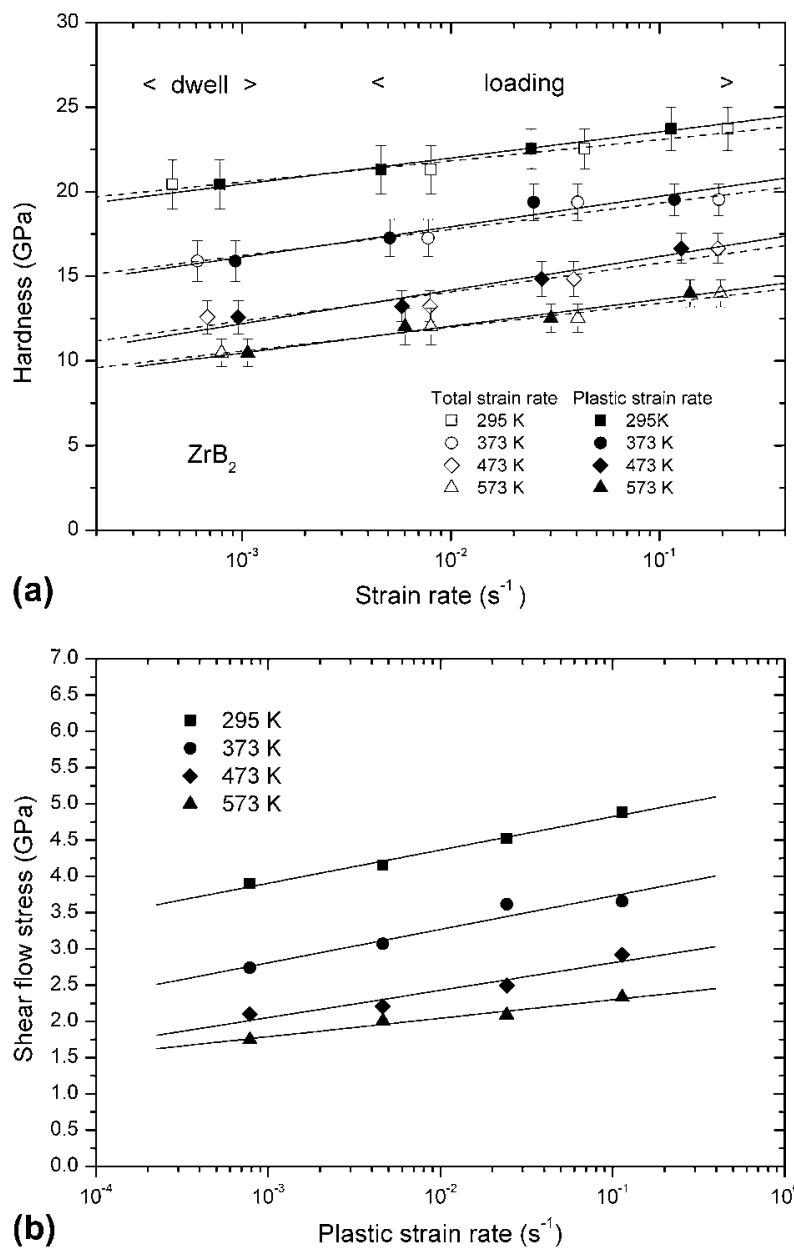

FIG. 5. (a) Hardness versus total or plastic strain rate for $\mathrm{ZrB}_{2}$ as measured for temperatures from 295 to $573 \mathrm{~K}$, (b) Shear flow stress versus plastic strain rate.

TABLE I. Value of $H_{\mathrm{s}}(\mathrm{GPa})$ in $H=H_{0}+H_{\mathrm{s}} \ln \varepsilon^{\prime}$, obtained by either fitting the data collected during loading alone or by including the data obtained from the dwell at maximum load using either the total strain rate or the plastic strain rate.

\begin{tabular}{lccccc}
\hline \hline & \multicolumn{2}{c}{ Total strain rate } & & \multicolumn{2}{c}{ Plastic strain rate } \\
\cline { 2 - 3 } \cline { 5 - 6 } & Loading & Loading + Dwell & & Loading & Loading + Dwell \\
\hline $\mathrm{ZrB}_{2}$-295 K & 0.74 & 0.54 & & 0.75 & 0.67 \\
$\mathrm{ZrB}_{2}-373 \mathrm{~K}$ & 0.71 & 0.69 & & 0.72 & 0.81 \\
$\mathrm{ZrB}_{2}$-473 K & 1.08 & 0.72 & & 1.11 & 0.84 \\
$\mathrm{ZrB}_{2}-573 \mathrm{~K}$ & 0.61 & 0.61 & & 0.62 & 0.68 \\
$6 \mathrm{H}-\mathrm{SiC}-295 \mathrm{~K}$ & -0.21 & 0.16 & & -0.21 & 0.19 \\
$4 \mathrm{H}-\mathrm{SiC}-295 \mathrm{~K}$ & 0.30 & 0.24 & & 0.31 & 0.32 \\
$\mathrm{f}-\mathrm{SiC}-295 \mathrm{~K}$ & 0.20 & 0.29 & & 0.20 & 0.37 \\
$\mathrm{c}-\mathrm{SiC}-295 \mathrm{~K}$ & 0.31 & 0.36 & & 0.31 & 0.46 \\
$\mathrm{c}-\mathrm{SiC}-373 \mathrm{~K}$ & 0.71 & 0.71 & & 0.73 & 0.91 \\
$\mathrm{c}-\mathrm{SiC}-473 \mathrm{~K}$ & 1.88 & 1.19 & & 2.01 & 1.60 \\
$\mathrm{TiN}$ & 0.48 & $\mathrm{n} / \mathrm{a}$ & 0.45 & $\mathrm{n} / \mathrm{a}$ \\
\hline \hline
\end{tabular}

physical meaning to it and that perhaps it should be considered as an adjustable parameter. The activation energy $\left(Q=\tau_{\mathrm{p}} \times V\right)$ is estimated to be $2.56 \pm 1.6 \times 10^{-19}$ $\mathrm{J}(1.61 \pm 1.0 \mathrm{eV})$. 


\section{B. SiC}

Hardness versus plastic strain rate results for the $\mathrm{SiC}$ system are shown in Fig. 6. Indentation experiments were performed on a relatively large grained, polycrystalline, AlN-doped SiC specimen at 295, 373, and $473 \mathrm{~K}$. A similar polycrystalline $\mathrm{SiC}$ with smaller grains and two single crystals $(4 \mathrm{H}$ and $6 \mathrm{H}$ polytypes) were indented at $295 \mathrm{~K}$. It is interesting to note that at $295 \mathrm{~K}$, the slope of data, i.e., the strain rate sensitivity of the hardness for both the single-crystal polytypes and both polycrystalline AlNdoped silicon carbides is very similar and yields a value of the order of $0.8 \mathrm{GPa}$ per decade of the strain rate. This indicates that the rate controlling mechanism is not influenced by the presence of grain boundaries. Moreover, it can be seen that the hardness of the single crystals is actually higher than that of the polycrystalline samples. Hence, the influence of orientation of the indents relative to the primary slip plane, which for $\mathrm{SiC}$ can be expected to be the basal plane, is stronger than the presence or absence of grain boundaries. This is reflected as well in the larger standard deviation on the results for the polycrystalline $\mathrm{SiC}$ samples, where different crystal orientations are probed which leads to more scatter. The scatter is higher for the fine grained material, in which more orientations will have been sampled than in the larger grained material. These observations are all consistent with the hardness being dominated by the magnitude of the lattice resistance and while grain boundaries will have some influence, at these relatively low temperatures their influence is limited. For the polycrystalline AlN-doped $\mathrm{SiC}$, as the temperature is increased, strain rate sensitivity is increased to about 1.6 GPa per decade of the strain rate at $373 \mathrm{~K}$ and $2.7 \mathrm{GPa}$ per decade of the strain rate at $473 \mathrm{~K}$.

The measured apparent activation volume from the change of shear stress, as derived from hardness, with plastic strain rate is $1.73 \times 10^{-29} \mathrm{~m}^{3}$, i.e., $4 \times b^{3}$. For the Burgers vector, a value of $0.154 \mathrm{~nm}$ was used as the flow in $\mathrm{SiC}$ is assumed to be by partial dislocations. ${ }^{35,57,58}$ The attempt frequency was again taken to be $10^{11} \mathrm{~s}^{-1}$. $^{56}$ The average estimate from the variation of shear stress with temperature for the Peierls stress is $12 \pm 1 \mathrm{GPa}$, and the mobile dislocation density is estimated as ranging from $4 \times 10^{10} \mathrm{~m}^{-2}$ to $2 \times 10^{14} \mathrm{~m}^{-2}$. The activation energy is estimated to be $1.75 \pm 0.4 \times 10^{-19} \mathrm{~J}(1.1 \pm 0.3 \mathrm{eV})$, which is markedly lower than the result of Fujita et al. ${ }^{59}$ $(3.4 \mathrm{eV})$ but close to the value of $1.67 \pm 0.16 \mathrm{eV}$ obtained by Pirouz et al. ${ }^{35}$

\section{C. (001) TiN}

Indentations were made on (001) TiN at 295 to $623 \mathrm{~K}$. The activation volume, $V$, was estimated using Eq. (4) from the three different loading rates at $295 \mathrm{~K}$. For the Peierls stress and mobile dislocation density, indentations were carried out at a loading rate at five temperatures.
Figure 7 shows hardness versus plastic strain rate at $295 \mathrm{~K}$. Also included in the figure are the hardness data from $0.04 \mathrm{~s}^{-1}$ plastic strain rate at different temperatures.

The measured apparent activation volume is $2.04 \times 10^{-29} \mathrm{~m}^{3}$, i.e., $0.75 \times b^{3}$. Here a value of $0.3 \mathrm{~nm}$ is used for $b$. The Peierls stress and mobile dislocation density are $5.9 \mathrm{GPa}$ and $1.46 \times 10^{10} \mathrm{~m}^{-2}$ respectively. The apparent activation energy, $\mathrm{Q}$, is of the order of $0.75 \mathrm{eV}$, i.e., $1.19 \times 10^{-19} \mathrm{~J}$.

\section{DISCUSSION}

Despite the limited strain rate sensitivity of the hardness of these hard ceramics, the values extracted from the results appear quite reasonable and compare favorably with literature values where available: the activation volume is found to be of the order of 1 to a few times the Burgers

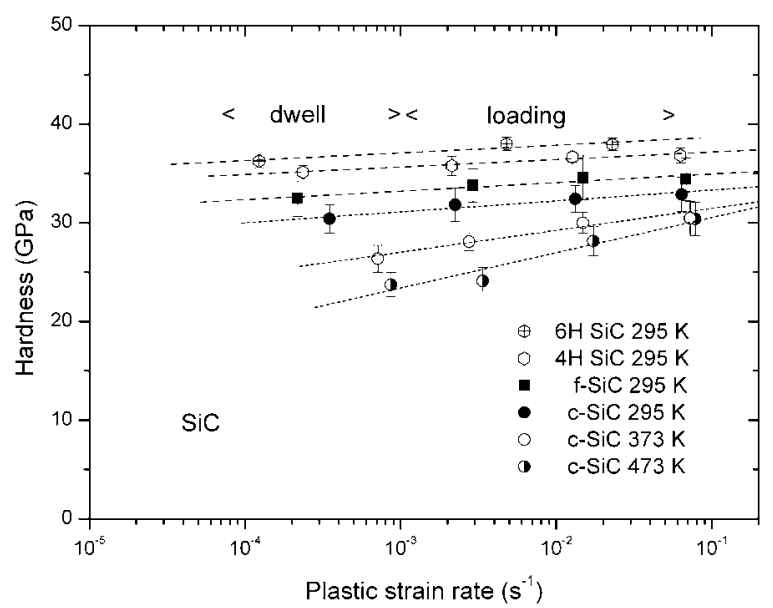

FIG. 6. Hardness versus plastic strain rate for $4 \mathrm{H}-\mathrm{SiC}$ and $6 \mathrm{H}-\mathrm{SiC}$ single crystals and $\mathrm{AlN}$-doped polycrystalline $\mathrm{SiC}$ with fine (f) or coarse (c) grains.

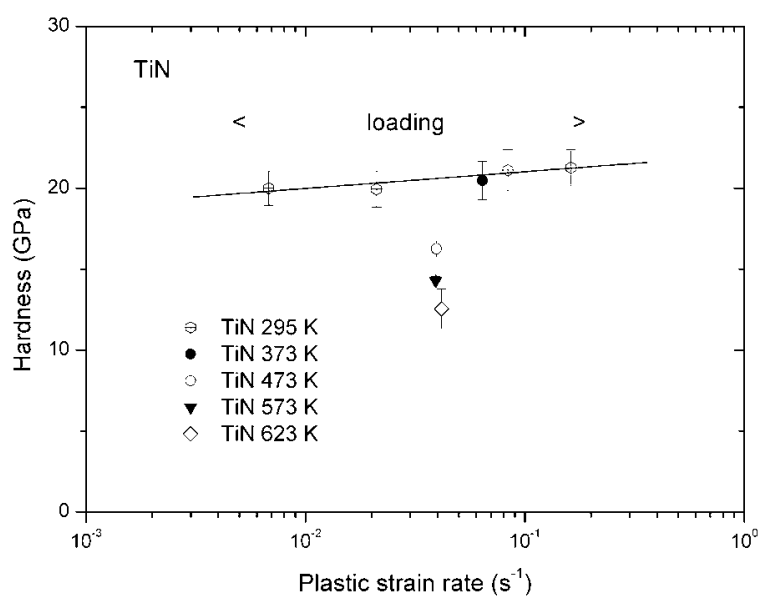

FIG. 7. Hardness versus plastic strain rate for (001) TiN single crystal at $295 \mathrm{~K}$. Also included are the hardness data at $0.04 \mathrm{~s}^{-1}$ plastic strain rate at 373 to $623 \mathrm{~K}$. 
vector cubed and the activation energy found for $\mathrm{SiC}$ is close to the value extracted from high temperature compression.

However, when measuring such limited strain rate effects, the contribution of instrumental drift, mainly arising from the thermal sensitivity of sensing devices in an indenter, is worth considering. This artifact superimposes the indentation data in such a way that it is hard to distinguish it from material response and hence it leads to miscalculation of material properties. In this work, the average thermal drift rate at room temperature is $0.02 \mathrm{~nm} \mathrm{~s}^{-1}$. The lowest rate of change of indentation depth with time during the loading stage of the test is encountered in the experiments with a loading time of up to $100 \mathrm{~s}$ and is of the order of $1-10 \mathrm{~nm} \mathrm{~s}^{-1}$ and hence 2 orders of magnitude larger than the instrumental drift so that the instrumental drift should have little influence on these measured strain rates.

During the dwell at constant load, the displacement rate due to material flow is much reduced. Taking a typical total displacement around $500 \mathrm{~nm}$, the instrumental drift of $0.02 \mathrm{~nm} \mathrm{~s}^{-1}$ can change the measured material strain rate by about $4 \times 10^{-5} \mathrm{~s}^{-1}$. This is still 2 orders of magnitude below the strain rate measured for $\mathrm{ZrB}_{2}$, see Fig. 6(a), but about $10 \%$ of the measured strain rate for $\mathrm{SiC}$, see Fig. 7. Above room temperature, the drift increased up to $0.2 \mathrm{~nm} \mathrm{~s}^{-1}$ and hence shifts in measured strain rate of the order of $4 \times 10^{-4} \mathrm{~s}^{-1}$ could occur. However, as temperature increases, the materials also become more strain rate sensitive so that the error is again of the order of $10 \%$.

It is worth emphasizing here that an important implication of this analysis is that slower indentation tests are more prone to increasing contribution from thermal drift, and researchers intending to perform long-duration indentation experiments must understand and control drift. Since in all cases the changes in displacement with time due to the material response will increase with load, whereas instrumental drift is load independent, experiments at larger loads are to be preferred as long as cracking can be avoided. These findings are in line with a recent extensive theoretical and experimental study by Everitt et al., ${ }^{38}$ who have analyzed in detail how the lack of an isothermal contact can lead to incorrect results.

The variation of shear flow stress with temperature for all the materials tested in this work, along with literature data from high-temperature compression tests on $\mathrm{SiC}$, is plotted in Fig. 8. It should be noted that the fact that the extrapolation is close to the high temperature results is probably a coincidence as obviously the dislocation densities and strain rates are very different in such compression tests and indentation tests. Of significance is that the rate of decay of the shear flow stress with temperature observed in the high temperature compression tests ${ }^{35,59}$ and the slope of the model are similar. Hence, intermediate temperature indentation tests allow estimating the key parameters for lattice-resistance-controlled glide, and probably within

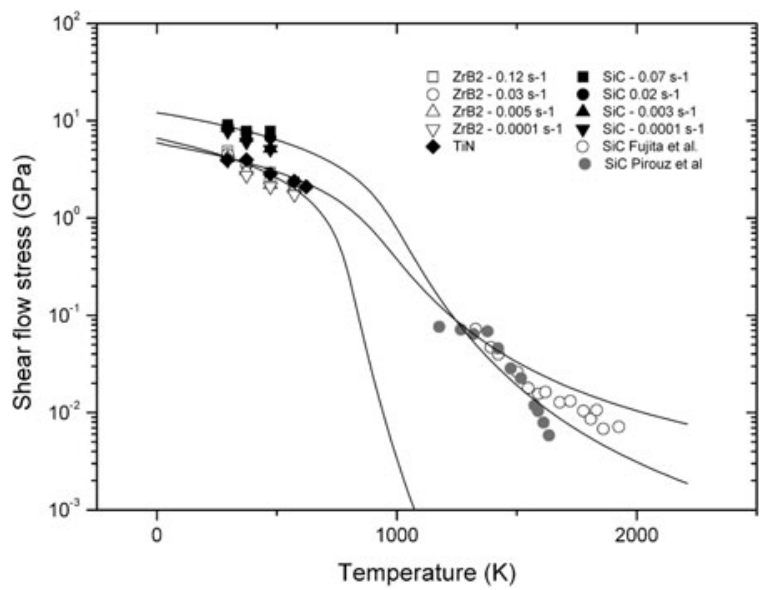

FIG. 8. The variation of the shear flow stress with temperature as determined from the hardness measurements in this investigation and from compression tests elsewhere, ${ }^{35,59}$ together with lines representing Eq. (3) using the parameters derived from the indentation tests for a midrange strain rate.

the same accuracy as can be achieved from high temperature compression tests. Noteworthy is also that $\mathrm{SiC}$ and $\mathrm{ZrB}_{2}$ appear to show quite similar rates of reduction in flow resistance with temperature, while the reduction in TiN appears less rapid.

It is demonstrated in this work that indentation can be a very effective technique for investigating kinetics of plastic deformation in ceramics. However, the use of a sharp tip Berkovich indenter during indentation tests, as done in this work, results in nonuniform deformation and invokes a complex multiaxial stress state in the deformed material in the plastic zone beneath it. As the data for $\mathrm{SiC}$ showed, this can lead to plastic anisotropy influencing the results. Moreover, to accommodate the shape change induced by the indenter potentially multiple slip systems might be activated, see e.g., Ref. 60 It is not entirely clear how the contributions of each of those slip systems contribute to the average hardness, although it has been suggested that the hardest slip system that needs to be activated would dominate. ${ }^{56}$ To circumvent this complexity, lately a micro/nanopillar compression test method has been developed in which uniaxial compression tests are carried out on small pillars, made by focused ion beam milling, using a flat-punch indenter. ${ }^{39,61}$ The small scale suppresses cracking making large plastic strains possible, even at room temperature. Therefore, such test might in future be the better tool to extract fundamental information about specific slip systems. However, while in principle extraction of quantitative data from such experiments is easier, the experiments themselves are quite complex and require careful sample preparation routines. Moreover, in many applications, the contact stresses are not dissimilar to those encountered in a hardness test and therefore as a near application test, hardness tests and the ability to extract information from it, even if it is some weighted average, 
can be expected to continue to play an important role in future materials development.

\section{CONCLUSIONS}

In this work, an analysis was presented of indentation hardness data from three ceramic materials, $\mathrm{ZrB}_{2}, \mathrm{SiC}$ (6H \& single polytypes and AlN-doped polycrystalline), and (001) TiN, to extract the fundamental deformation parameters at 295 to $623 \mathrm{~K}$. The measured apparent activation volume for $\mathrm{ZrB}_{2}$ is $1.24 \times b^{3}$. For polycrystalline $\mathrm{SiC}$, it is estimated to be $4 \times b^{3}$ and $0.76 \times b^{3}$ for $(001)$ TiN. These are in line with the reported values for ceramics in literature. The Peierls stress values for $\mathrm{ZrB}_{2}$, $\mathrm{SiC}$, and (001) TiN are 6.6 $\pm 0.7,12.3 \pm 0.5$, and $5.9 \mathrm{GPa}$, respectively. Calculated activation energies are of the order of lattice-controlled dislocation glide for the three tested materials. Hence, indentation can be a very effective technique for investigating kinetics of plastic deformation in ceramics at ambient and moderately elevated temperatures provided thermal drift can be kept under control.

Finite difference simulations demonstrated that there is a significant difference between the plastic strain rate and the total strain rate for materials showing substantial elastic deformation (i.e., large $H / E$ ). For such materials, the measured total strain rates must be converted into plastic strain rates, which require a reduction during loading and an increase during the dwell at maximum load. This results from the fact that during loading both the elastic and the plastic displacement increases, whereas during the hold at maximum load, the plastic displacement continues to increase but the total elastic displacement decreases. By carrying out a wide range of simulations, the equations needed to make such corrections have been derived.

The importance of quantification of thermal drift in instrumented indentation has been stressed: for the strain rates during loading, the drift is insignificant, whereas during the dwell the drift introduced some uncertainty for SiC. Thermal drift can potentially shift results and is more likely to do so during slow indentation experiments where the rate of change of indentation depth is of the order of measured drift. As the relative influence of drift and material straining is reduced when the load is increased, experiments should be carried out at the largest applied forces for which plasticity remains the only dominant mechanism.

\section{ACKNOWLEDGMENTS}

Authors wish to thank Engineering \& Physical Sciences Research Council of the United Kingdom for funding this research through Grant number EP/F033605/1, and Prof. Leif Johansson, Linköping University, Sweden for providing the TiN single crystal.

\section{REFERENCES}

1. J.H. Westbrook: The temperature dependence of hardness of some common oxides. Rev. Hautes Temper. et Refract. 3(1), 47 (1966).

2. X.J. Ren, R.M. Hooper, C. Griffiths, and J.L. Henshall: Indentationsize effects in single-crystal MgO. Philos. Mag. A 82(10), 2113 (2002).

3. C.H. Chen, Y. Xuan, and S. Otani: Temperature and loading time dependence of hardness of LaB6, YB6 and TiC single crystals. J. Alloy. Compd. 350(1-2), L4 (2003).

4. L. Bsenko and T. Lundström: The high-temperature hardness of $\mathrm{ZrB}_{2}$ and $\mathrm{HfB}_{2}$. J. Less Common Met. 34(2), 273 (1974).

5. C. Dellacorte and D.L. Deadmore: Vickers Indentation Hardness of Stoichiometric and Reduced Single Crystal $\mathrm{TiO}_{2}$ (rutile) from 25 to 800 C. (NASA Technical Memorandum 105959, 1993).

6. I.V. Gridneva, Yu V. Mil'man, G.A. Rymashevskii, V.I. Trefilov, and S.I. Chugunova: Effect of temperature on the strength characteristics of zirconium carbide. Powder Metall. Met. Ceram. 15(8), 638 (1976).

7. Farber, B.Y., V.I. Orlov, and A.H. Heuer: Energy dissipation during high temperature displacement-sensitive indentation in cubic zirconia single crystals. Physica Status Solidi A 166(1), 115 (1998).

8. D. Tabor: Hardness of Metals (Oxford, Clarendon Press, 1951).

9. D. Tabor: The physical meaning of indentation and scratch tests. Br. J. Appl. Phys. 7, 159 (1956).

10. A.G. Atkins and D. Tabor: Plastic indentation in metals with cones. J. Mech. Phys. Solids 13, 149 (1965).

11. D.M. Marsh: Plastic flow in glass. Proc. R. Soc. A 279, 420 (1963).

12. K.L. Johnson: The correlation of indentation experiments. J. Mech. Phys. Solids 18, 115 (1970).

13. Y.T. Cheng and C.M. Cheng: What is indentation hardness? Surf. Coat. Tech. 133-134, 417 (2000).

14. L.J. Vandeperre, F. Giuliani, and W.J. Clegg: Effect of elastic surface deformation on the relation between hardness and yield strength. J. Mater. Res. 19(12), 3704 (2004).

15. L.J. Vandeperre, F. Giuliani, S.J. Llyod, and W.J. Clegg: The hardness of silicon and germanium. Acta Mater. 55(18), 6307 (2007).

16. L.E. Samuels and T.O. Mulhearn: An experimental investigation of the deformed zone associated with indentation hardness impressions. J. Mech. Phys. Solids 5, 125 (1957).

17. S.S. Gupte and C.F. Desai: Vickers hardness anisotropy and slip system in zinc (tris) thiourea sulphate crystals. Cryst. Res. Technol. 34(10), 1329 (1999).

18. J.L. Bucaille, S. Stauss, E. Felder, and J. Michler: Determination of plastic properties of metals by instrumented indentation using different sharp indenters. Acta Mater. 51(6), 1663 (2003).

19. T.W. Capehart and Y.T. Cheng: Determining constitutive models from conical indentation: Sensitivity analysis. J. Mater. Res. 18(4), 827 (2003)

20. Ma, X., F. Yoshida, and K. Shinbata: On the loading curve in microindentation of viscoplastic solder alloy. Mat. Sci. Eng. A. 344 (1-2), 296 (2003).

21. Z.F. Yue, J.S. Wan, and Z.Z. Lu: Determination of creep parameters from indentation creep experiments. Appl. Math. Mech. Engl. Ed. 24(3), 307 (2003).

22. S.G. Roberts, P. Pirouz, and P.B. Hirsch: Doping effects on indentation plasticity and fracture in germanium. J. Mater. Sci. 20, 1739 (1985).

23. J.E. Bradby, J.S. Williams, J. Wong-Leung, S.O. Kucheyev, M.V. Swain, and P. Munroe: Spherical indentation of compound semiconductors. Philos. Mag. A 82(10), 1931 (2002).

24. J.H. Ahn, E. Jeon, Y. Choi, Y. Lee, and D. Kwon: Derivation of tensile flow properties of thin films using nanoindentation technique. Curr. Appl. Phys. 2(6), 525 (2002).

25. J.J. Gilman: Hardness-a strength microprobe, in The Science of Hardness Testing and its Applications, edited by J.H. Westbrook 
and H. Conrad (American Society for Metals, Metals Park, Ohio, 1973).

26. K. Suzuki, Y. Benino, T. Fujiwara, and T. Komatsu: Densification energy during nanoindentation of silica glass. J. Am. Ceram. Soc. $\mathbf{8 5}(12), 3102$ (2002).

27. F. Tancret and F. Osterstock: Indentation behavior of porous materials: Application to the Vickers indentation cracking of ceramics. Philos. Mag. 83(1), 125 (2003).

28. R.F. Cook and G.M. Pharr: Direct observation and analysis of indentation cracking in glasses and ceramics. J. Am. Ceram. Soc. 73(4), 787 (1990).

29. G.M. Pharr, W.C. Oliver, and D.S. Harding: New evidence for a pressure-induced phase transformation during the indentation of silicon. J. Mater. Res. 6(6), 1129 (1991).

30. D.R. Clarke, M.C. Kroll, P.D. Kirchner, and R.F. Cook: Amorphization and conductivity of silicon and germanium induced by indentation. Phys. Rev. Lett. 60(21), 2156 (1988).

31. T. Juliano, Y. Gogotsi, and V. Domnich: Effect of indentation unloading conditions on phase transformation induced events in silicon. J. Mater. Res. 18(5), 1192 (2003).

32. J.S. Williams, Y. Chen, J. Leung-Wong, A. Kerr, and M.V. Swain: Ultra-micro-indentation of silicon and compound semiconductors with spherical indenters. J. Mater. Res. 14(6), 2338 (1999).

33. G.D. Quinn, P. Green, and K. Xu: Cracking and the indentation size effect for knoop hardness of glasses. J. Am. Ceram. Soc. 86(3), 441 (2003).

34. B. Baufeld, U. Messerschmidt, M. Bartsch, and M. Baither: Plasticity of cubic zirconia between $700{ }^{\circ} \mathrm{C}$ and $1150{ }^{\circ} \mathrm{C}$ observed by macroscopic compression and by in-situ tensile straining tests. Key Eng. Mater. 97-98, 431 (1994).

35. P. Pirouz, J.L. Demenet, and M.H. Hong: On transition temperatures in the plasticity and fracture of semiconductors. Philos. Mag. A 81(5), 1207 (2001).

36. C.A. Schuh: Nanoindentation studies of materials. Mater. Today 9(5), 32 (2006)

37. C.A. Schuh: Nanoindentation and contact-mode imaging at high temperatures. J. Mater. Res. 21(3), 725 (2006).

38. N.M. Everitt, M.I. Davies, and J.F. Smith: High temperature nanoindentation - the importance of isothermal contact. Philos. Mag. 91(7), 1221 (2011).

39. S. Korte and W.J. Clegg: Micropillar compression of ceramics at elevated temperatures. Scr. Mater. 60(9), 807 (2009).

40. F. Monteverde and R. Savino: Stability of ultra-high-temperature $\mathrm{ZrB}_{2}$-SiC ceramics under simulated atmospheric re-entry conditions. J. Eur. Ceram. Soc. 27(16), 4797 (2007).

41. E. Opila, S. Levine, and J. Lorincz: Oxidation of $\mathrm{ZrB}_{2^{-}}$and $\mathrm{HfB}_{2-}$ based ultra-high temperature ceramics: Effect of Ta additions. J. Mater. Sci. 39(19), 5969 (2004).

42. N. Ur-rehman, P. Brown, and L.J. Vandeperre: Evolution of the AlN distribution during sintering of AlN doped SiC. Ceram. Eng. Sci. Proc. 31(5), 231 (2010).

43. N. Ur-rehman, P. Brown, and L.J. Vandeperre: The role of carbon in processing hot pressed aluminium nitride doped silicon carbide. Ceram. Eng. Sci. Proc. 31(2), 27 (2010).
44. J. Wang, F. Giuliani, and L.J. Vandeperre: The effect of load and temperature on hardness of $\mathrm{ZrB} 2$ composites. Ceram. Eng. Sci. Proc. 31(2), 59 (2010).

45. W.C. Oliver and G.M. Pharr: An improved technique for determining hardness and elastic modulus using load and displacement sensing indentation experiments. J. Mater. Res. 7(6), 1564 (1992).

46. I.N. Sneddon: Boussinesq's problem for a rigid cone. Proc. Cambridge Philos. Soc. 44, 492 (1948).

47. G.D. Quin, P.J. Patel, and I. Lloyd: Effect of loading rate upon conventional ceramic microindentation hardness. J. Res. Natl. Inst. Stand. Technol. 107, 299 (2002).

48. L.J. Vandeperre, N. Ur-rehman, and P. Brown: Strain rate dependence of hardness of AlN doped SiC. Adv. Appl. Ceram. 109(8), 493 (2010)

49. J. Hay, P. Agee, and E. Herbert: Continuous stiffness measurement during instrumented indentation testing. Exp. Tech. 34(3), 86 (2010).

50. M.J. Cordill, N.R. Moody, and W.W. Gerberich: Effects of dynamic indentation on the mechanical response of materials. J. Mater. Res. 23(06), 1604 (2008).

51. G.M. Pharr, J.H. Strader, and W.C. Oliver: Critical issues in making small-depth mechanical property measurements by nanoindentation with continuous stiffness measurement. J. Mater. Res. 24(03), 653 (2009).

52. A.A. Elmustafa, S. Kose, and D.S. Stone: The strain-rate sensitivity of the hardness in indentation creep. J. Mater. Res. 22(4), 926 (2007).

53. R. Hill: The Mathematical Theory of Plasticity. (Oxford, Clarendon Press, 1950).

54. J.S. Haggerty and D.W. Lee: Plastic deformation of $\mathrm{ZrB}_{2}$ single crystals. J. Am. Ceram. Soc. 54(11), 572 (1971).

55. D. Ghosh, S. Ghatu, and G.R. Bourne: Room-temperature dislocation activity during mechanical deformation of polycrystalline ultra-high-temperature ceramics. Scr. Mater. 61, 1075 (2009).

56. H.J. Frost and M.F. Ashby: Deformation Mechanism Maps: The Plasticity and Creep of Metals and Ceramics. (Oxford, Pergamon Press, 1982).

57. Ohsawa, K., H. Koizumi, H.O.K. Kirchner, and T. Suzuki: The critical stress in a discrete Peierls-Nabbaro model. Philos. Mag. A. 69(1), 171 (1994).

58. W. Clegg, L. Vandeperre, and J. Pitchford: Energy changes and the lattice resistance. Key Eng. Mater. 317-318, 271 (2006).

59. S. Fujita, K. Maeda, and S. Hyodo: Dislocation glide motion in $6 \mathrm{H}$ $\mathrm{SiC}$ single crystals subjected to high-temperature deformation. Philos. Mag. A 55(2), 203 (1987).

60. S.J. Lloyd, A. Castellero, F. Giuliani, Y. Long, K.K. McLaughlin, J.M. Molina-Aldareguia, N.A. Stelmashenko, L.J. Vandeperre, and W.J. Clegg: Observations of nanoindents via cross-sectional transmission electron microscopy: A survey of deformation mechanisms. Proc. R. Soc. London, Ser. A 461(2060), 2521 (2005).

61. M.D. Uchic, D.M. Dimiduk, J.M. Florando, and W.D. Nix: Sample dimensions influence strength and crystal plasticity. Science 305(5686), 986 (2004). 


\section{$\nabla$ Micro Materials}

Excellence in Nanomechanics

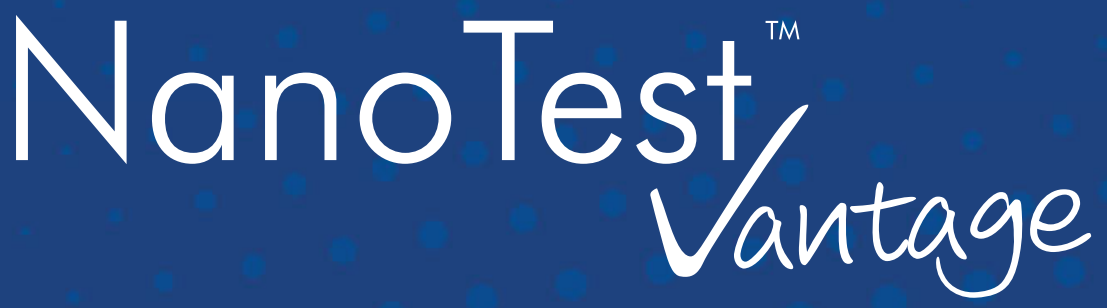

Introducing the new NanoTest Vantage nanomechanical test centre from

Micro Materials Ltd

Get the full picture of your material performance using:

- Nanoindentation

Nano-scratch and wear

> Nano-impact and fatigue

Nano-fretting

The NanoTest Vantage allows the user full environmental control, allowing tests to be carried out:

1) At elevated temperatures up to $750^{\circ} \mathrm{C}$

1) At sub-ambient temperature down to $-30^{\circ} \mathrm{C}$

$\checkmark$ In liquids

V Under controlled humidity

$\checkmark$ In reduced oxygen environments

Visit www.micromaterials.co.uk today and see what the NanoTest Vantage can do for you.
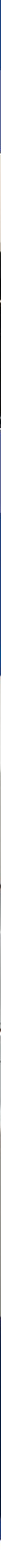